\title{
Brief Intense TENS Efficacy in Post - Herpetic Neuralgia of the Sciatic Nerve.
}

\author{
Z. Mowafy Emam Mowafy* and Akef A Khowailed** \\ * Physical Therapy Department for Surgery, Faculty of Physical Therapy, Cairo \\ University, Egypt. \\ ** Physiology Department Faculty of Medicine, Cairo University, Egypt.
}

\begin{abstract}
This study has been conducted to determine efficacy of the brief intense TENS on pain in patients with post - herpetic neuralgia of sciatic nerve. Forty patients ( 25 males and 15 females) suffering from post -herpetic neuralgia with no other systemic or metabolic disorders, participated in this study. Their age ranged from 25 to 40 years $(X=34.35 \pm 1.11)$. They were divided randomly into two groups of equal number and consented to receive brief intense TENS (for the first experimental group) and placebo TENS (for second control group), from a dual - channel TENS unit along the sciatic nerve course. Assessment of pain was carried out before and after treatment which include a session for 10 minutes conducted every twelve hours daily, at the same times on 3 consecutive days. Non significant difference in serum cortisol level was recorded before starting the treatment between the two groups as it was 34.35 and 34.30 for the first and second group respectively. Data collected at the end of the treatment program showed that averages of Serum Cortisol Level (SCL) were 26.59 $\pm 2.71 \mu \mathrm{g} / \mathrm{dl}$ and $34.28 \pm 3.49 \mu \mathrm{g} / \mathrm{dl}$ in the first and second groups respectively. Results showed a significant reduction in SCL at the end of the treatment program in the first group only. So the brief intense TENS may be considered as an effective tool in modulating the post -heretic neuralgia of the sciatic nerve.
\end{abstract}

\section{Introduction}

In about 1936 Rovenstine started the first pain clinic, a nerve block clinic, at new Yourk. In 1961 Bonica established the first more broadly based pain relief clinics in Tacoma and Washington and Alexander developed a clinic in Mckinney, Texas .The first pain relief clinics in Europe were established in Great Britain, ${ }^{4.59 .10}$.

Physiotherapists became directly involved with care of patients attending pain clinics during the $1970 \mathrm{~s},{ }^{1.6 .13}$.

The actual involvement of physiotherapists in the multidisciplinary team of pain clinics was often in the form of TENS application, ${ }^{7.11 .15 .20}$.
Now in some pain clinics in USA and UK role of physiotherapist has broadened to encompass the greater need for assessment in differential diagnosis and the appropriate use of a Variety of treatment modalities, ${ }^{2.8}$.

Post - herpetic neuralgia (Shingles) is the result of a virus (herpes zoster) that attacks one or more dorsal root ganglia and corresponding sensory nerves. Post herpetic neuralgia frequently involves the trigeminal, intercostals and the major extremity peripheral nerves, ${ }^{3.23 .27}$.

Diagnosis of post- herpetic neuralgia is initially difficult when skin eruptions (vesicles or blisters) are not 
yet apparent and the only complaint is pain, so a previous history of chickenpox may aid in the diagnosis, ${ }^{16.19}$.

This initial phase commonly lasts for 2 to 5 days prior to the appearance of the skin rash. Skin rash follows the involved nerve as well as its sensory (dermatomal) area and may last for up to 6 weeks, ${ }^{12.22 .26}$.

The acute phase is characterized by burning pain that frequently decreases as regeneration of new fibers occurs. Periods of burning ,stabbing and shooting pains occurring spontaneously day and night persist for months or years after the acute phase, ${ }^{14.21 .25}$.

The involved area becomes hyperesthetic and non -noxious stimuli can cause a painful response. The severe pain of post -herpetic neuralgia may be triggered by light touch, clothing rubbing against the skin, noise, temperature changes, sweating and emotional upsets, ${ }^{17.18}$.

Frequently there is a delay of a few seconds in the onset of pain following non- noxious stimuli and that phenomenon may be attributed to the slow regeneration of the fasterconducting, large -A- fibers, process of summation and the delayed conduction velocity, ${ }^{10.15 .20}$.

Most of the endogenous opiate system, negative feedback loop, locus ceruleus-norepinephrine-

neurohormonal system and the diffuse noxious inhibitory controls were involved in the process of pain modulation, and the serum betaendorphin level would be criterion for the stress of pain and the pain relief, ${ }^{15.22}$.

Secretion of beta- endorphins is associated with secretion of ACTH and cortisol, therefore estimation of the SCL became an effective new objective tool for pain measurement. Normal cortisol level ranged from 9-25 $\mu \mathrm{g} / \mathrm{dl}$ at morning and patients with painful condition tended to have higher than normal SCL, ${ }^{15.22}$.

\section{Material and Methods \\ Subjects:-}

Forty patients (25 males and 15 females) ranging in age from 25 to 40 years, selected from the out-clinics of Kasr -El -Aini (Cairo University Hospitals). Patients were not familiar with the technique of the brief intense TENS mode and suffering from postherpetic neuralgia of the sciatic nerve with no other systemic or metabolic disorders.

Patients were divided equally in number into two groups. They were received brief intense TENS for the first (study) group and placebo TENS for second (control) group. All patients were received the same physiotherapeutic regimen, the same medical and nursing care.

\section{Instrumentation:-}

A dual channel TENS stimulator, Model DH- 808, made by DAE HAN in Korea. The stimulation parameters and the principal characteristics of the brief intense TENS were, $100 \mathrm{~Hz}$ for frequency, $300 \mu \mathrm{Sec}$ for the pulse width, $80 \mathrm{~mA}$ for the intensity (strong to level of tolerance, non -rhythmic muscle fasciculation or titanic contraction

\section{Procedures:-}

Evaluation :-

Estimation of SCL was carried out before and after the treatment program (10 minutes session every 12 hours daily, at the same times on 3 consecutive days, in the form of 5 minutes application then 3 minutes rest followed by another 5 minutes application). A venous blood sample in 
the morning, centrifuged and stored at $20^{\circ} \mathrm{C}$ till analyzed.

\section{Treatment :-}

According to the aforementioned stimulation parameters and principal characteristics of the brief intense TENS, the dual channel TENS stimulator was used to administer the brief intense TENS via 4 self- adhesive sterile electrodes, that were placed in a linear pathway, unilaterally over the affected side from up to down side with patient prone as follow:

First electrode: at 15-S1 (errectrospinae motor point) level paravertebrally (channel one).

Second electrode: on the tender buttock, upper motor point of gluteus maximus (channel one).

Third electrode: at the midpoint between ischial tuberosity and greater trochanter at level of buttock and posterior upper thigh (channel two).

Fourth electrode: just superior to popliteal crease (channel two).

\section{Data analysis:-}

The serum cortisol level was measured before and after the treatment program in both control and study groups. Collected data were fed into computer for the statistical analysis, descriptive statistics as mean, standard deviation, minimum, and maximum were calculated for each group. The $\mathrm{t}-$ Test was done to compare the mean difference of the two groups before and after application and within each group. Alpha point of 0.05 was used as a level of significance.

\section{Results :-}

In the present study, the effect of the brief intense TENS on SCL in post herpetic neuralgia of sciatic nerve was investigated. As shown in table (1) and figure (1), the mean value of the SCL, before treatment was $(34.35 \pm 3.51) \mu \mathrm{g} / \mathrm{dl}$ in the first group, while after treatment was $(26.59 \pm 2.71) \mu \mathrm{g} / \mathrm{dl}$. These results revealed a significant reduction in SCL, $(\mathrm{P}<0.05)$. But in the second group, the mean value of the SCL, before treatment was $(34.30 \pm 3.50) \mu \mathrm{g} / \mathrm{dl}$, while after treatment was $(34.28 \pm 3.49) \mu \mathrm{g} / \mathrm{dl}$, which revealed a non -significant difference in SCL, $(\mathrm{P}>0.05)$.

Table (1): comparison of mean values of SCL before and after treatment in both Groups.

\begin{tabular}{|c|c|c|c|c|c|}
\hline \multirow{2}{*}{} & \multicolumn{2}{|c|}{$\begin{array}{c}\text { Before } \\
\text { Treatment }\end{array}$} & \multicolumn{2}{c|}{$\begin{array}{c}\text { After } \\
\text { Treatment }\end{array}$} & \multirow{2}{*}{$\begin{array}{c}\text { P. } \\
\text { Value }\end{array}$} \\
\cline { 2 - 5 } & $\mathrm{X}$ & SD & X & SD & Sa.05 \\
\hline $\begin{array}{c}\text { First } \\
\text { Group }\end{array}$ & 34.35 & 3.51 & 26.59 & 2.71 & $<0.05$ \\
\hline $\begin{array}{c}\text { Second } \\
\text { Group }\end{array}$ & 34.30 & 3.50 & 34.28 & 3.49 & $>0.05$ \\
& & & & & \\
\hline
\end{tabular}

$\square$ Befor Treatment $\square$ Afte Treatment

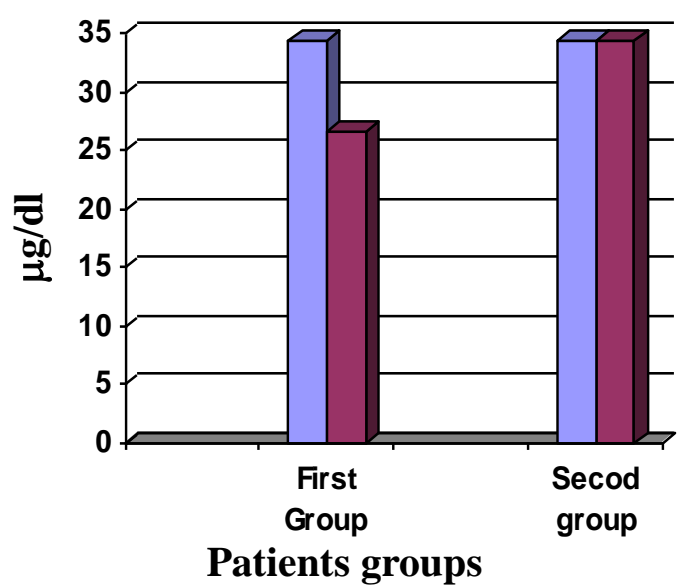

Fig. (1): mean values of SCL before and after treatment in both groups

\section{Discussion:-}

Pain is a warning signal that helps to protect the body from tissue damage. Sherrington defined pain as a 
psychological adjunct to a protective reflex, the purpose of which is to cause the affected tissue to be withdrawn from the potentially noxious stimuli. Pain, unlike most other sensory modalities, has an essential function in survival, ${ }^{8.10 .18}$.

The sensation of pain originates from the activation of nociceptive primary afferents by intense thermal, mechanical, or chemical stimuli. These nociceptor sites are small, free nerve endings in the numerous tissues of the body, ${ }^{11.17 .26}$.

The nature of pain as a specific entity remains obscure. Identification of specific fiber types transmitting pain sensation has been physiologically ascertained, and there is evidence that these painful sensations are carried within specific tracts in the spinal cord, ${ }^{5.18 .20}$.

However, there is no guarantee that interruption of these tracts will eliminate or modify pain sensation completely, as has been noted in causalgia, phantom pain, and pain from cancer, ${ }^{5.18 .21 .}$.

The findings of the present study showed no significant differences in the pre-treatment records of the SCL between the mean values of the first study and the second control groups.

Also results of the control group were compared between before and after placebo TENS and showed nonsignificant changes in SCL.

But results of the study group revealed a significant reduction in the mean values of SCL, after application of the brief intense TENS, when compared against pre application results.

Also significant difference was recorded between the mean values of SCL in the control and study groups after the suggested period of treatment as it was significantly reduced in the study group.

Significant differences showed in the study group is consistent with those observed and recorded by Hymes 1974; Lush et al., 1972; Roberts 1978; Kattabei and Hashem, 1997; Mowafy and Abd Elghany 2000; Cooperman 1975; Sweeny, 1980 and Pike, 1978.

Results of this study supports the expectation that brief intense TENS could be significantly effective in decreasing post - herpetic neuralgia of the sciatic nerve, as manifested by decreased SCL.

Brief intense TENS may be effective via its analgesic and depressor effect in decreasing the dominant sympathetic tone in painful conditions, decreasing edema and inflammation.

\section{Conclusion:-}

Electro analgesia that can be achieved via the brief intense TENS application may be attributed to the rapid increase in the endogenous opiates as well as to rapid decrease in conduction of the nerve action potential of $\mathrm{A}$-delta fibers which are the pain mediators.

\section{References:-}

1. Andersson, SA., : Pain control by sensory stimulation : second world congress on pain. Montreal. Canada.PainAbstract1:97,1978.

2. August, P.J. :Iatrogenic skin disease. Practitioner224:471-478,1980.

3. Augustinssion, L.E, Bohlin,P. and Bundsen,P.: Pain relief during delivery by TENS. Pain4:59,1997.

4. Bates,J.A. and Nathan, P.W.:TENS for chronic pain. Anaethesia. 35: 817,1980 .

5. Bates,j.A. and Nathan,P.W. :TENS for Chronic pain. Anaesth. 35: $817,1980$.

6. Bentt,G.L.: Neuropathic pain: Wall, P.D Melzack, R (ed) textbook of pain 
(3 rd. ed), PP201-224. Edinburgh: Churehill Livingston, 1994.

7. Bonica,J.J. (ed): The management of pain ed2, vols1 and 2, Lea of febiger, Philadelphia, 1990.

8. Bromage, P.R.; Camoresi, E. and chestnut,D.: Epidural Narcotics for post-operative analgesia. Anaesth. cleve.59:473-480.1980.

9. Cooperman, A.M.; useof TENS in control of postoperative pain, Surg Forum 26:77,1975.

10. Gersh, M.R. and Wolf, S.L.: (II) Application of TENS in the management of patients with pain. JAPTA. 65 (3): 314-1985.

11. Hymes, A.C.: Electrical surface stimulation for treatment and prevention of ilues and atelectasis. Surg forum, 25:223,1974.

12. Kattabei,O. and Hashem, S.: Low intensity laser therapy efficacy in chronic sciatic pain syndrome. Bull.fac.ph.th.Cairo univ., vol2. No(2).pp22-30,1997.

13. Keefe, F. of Kashikar - Zuck, S., opiteck, J ,Hage,E., Dalrymple, L., and Bulumenthal, $\mathbf{J}$ : pain in arthritis and musculoskeletal disorders. Jospt(24):279-286,1996.

14. Kramis, R., Robert, W. and Gillette, R.: Non- nociceptive aspect of persistent musculoskeletal pain. LOSPT, (24) 4 : 225-265, 1996.

15. Long,D.M : Fifteen years of TENS for pain control. stereotact. funct. neurosurg. 56 (1) : 219,1991.

16. Lush, D., Thrope, J. Richardson, D. and Bower, D.; The effect of epidural analgesia on the adrenocrtical response to surgery. Br. J. Anaesth. (44) : PP.1163-1169,1972.

17. Mayer, T.G. Getche, R.J. and kishino, N.: Objective assessment of pain following industrial injury. A prospective study with comparison group and one -year follow-up. Spin.10:482-93, 1985.

18. Mersky,H.(ed):classification of chronic pain :description of chronic syndromes and definition of pain terms. Pain(suppl3):s1,1986.

19. Mowafy,Z.: Different TENS modes in relation to $\mathrm{MCV}$ in peripheral burn neuropathy. Unpublished. ph. D. thesis , fac. ph, th.cairo univ.1998.

20. Pike,P.M.H.: TENS :its use in the management of postoperative pain. Anaesth.33:165,1978.

21. Roberts,H.J: TENS in the management of pancretitis pain. south Med J.71;395,1978.

22. Secuteri,F.: Endorphins, opiate receptors and migraine headache. Headache.71:253-257,1978.

23. Sluka,K.A.:pain mechanism :involved in musculoskeletal disorders: JOSPT (24)4:240-254,1996.

24. Steven,A.S.:Role of endorphins in pain modulation. $\mathrm{J}$ of ortho and sports ph.th.4(3):200-205,1983.

25. Sweeny,A.S. :Key to postoperativepain. AORNJ .32:391, 1980.

26. Vander A.R. and Mcgrath,K.A.: TENS in treatment of postoperative pain. Am.J.Surg.130:388,1975.

27. Weinstein ,M.C.,Coley, C.M. and Richter J.M.: Medical management of gallstones. J.Gen. Intern., Med.5:277284,1990 


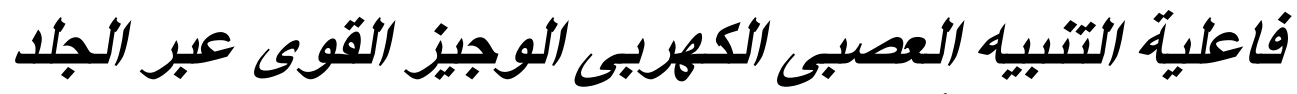 على ألم العصب الوركى بعد القوبياء
}

\author{
** زكريا موافى إمام موافى ، عاكف خويلا

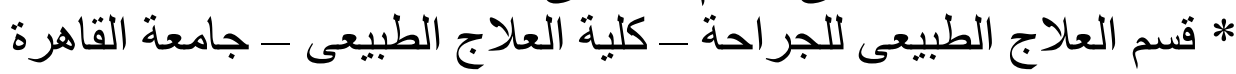

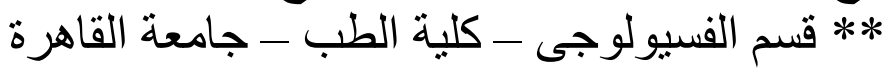

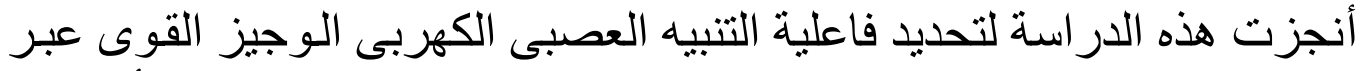

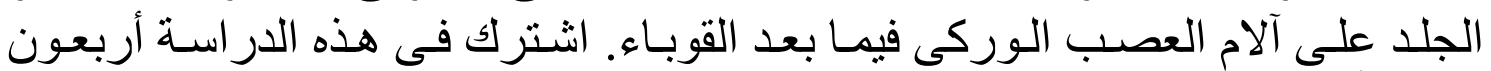

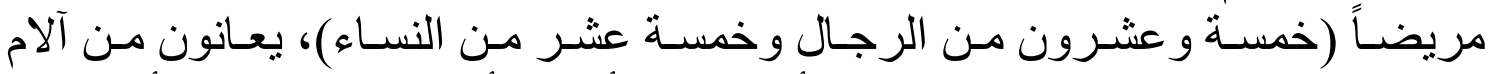

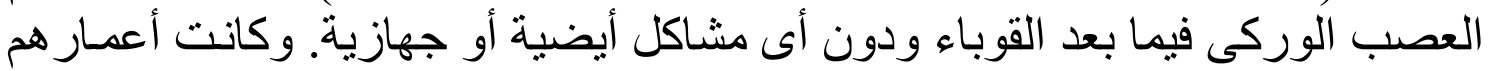

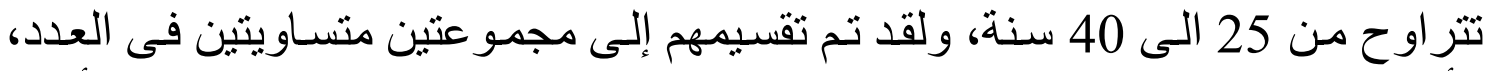

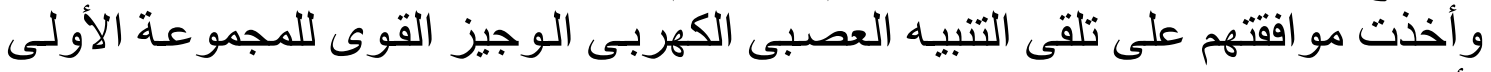

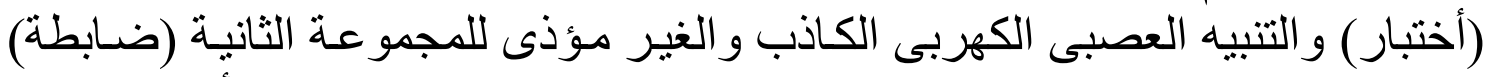

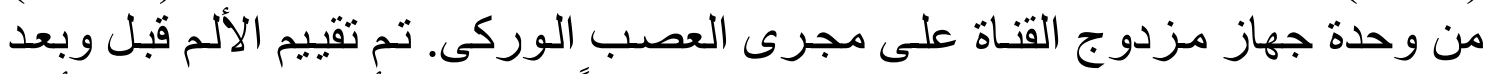

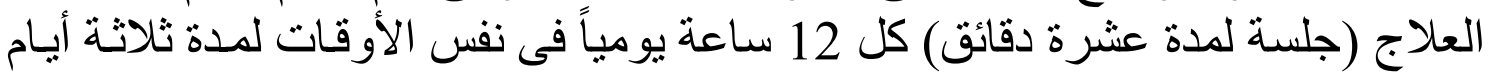
متتالية بو اسطة قياس مستوى كورتيزول

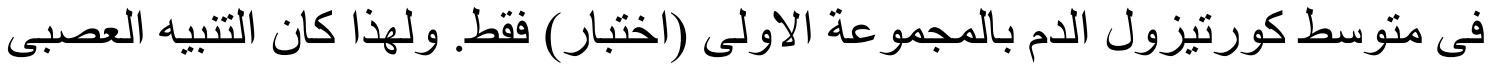

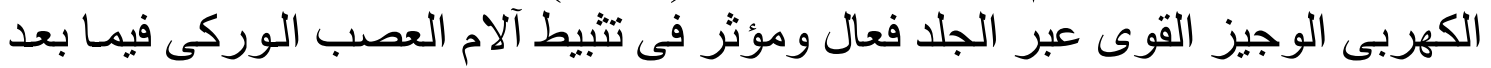
القوباء. 